\title{
PUBLISHER CORRECTION OPEN Publisher Correction: Two-dimensional materials with piezoelectric and ferroelectric functionalities
}

\author{
Chaojie Cui ${ }^{1}$, Fei Xue ${ }^{2}$, Wei-Jin Hu iD $^{3}$ and Lain-Jong Li $\mathbb{D D}^{2}$ \\ npj 2D Materials and Applications (2018)2:24 ; doi:10.1038/s41699-018-0067-1
}

Correction to: npj 2D Materials and Applications https://doi.org/ 10.1038/s41699-018-0063-5, Published online 22 June 2018

In the original published version of this Article, Wei-Jin Hu was incorrectly listed as being affiliated with Corporate Research and Chief Technology Office, Taiwan Semiconductor Manufacturing Company, 30075, Hsinchu, Taiwan. This has now been updated to be the Shenyang National Laboratory for Materials Science, Institute of Metal Research (IMR), Chinese Academy of Sciences (CAS), Shenyang 110016, China. This has been corrected in the HTML and PDF versions of the Article.

\begin{abstract}
Open Access This article is licensed under a Creative Commons Attribution 4.0 International License, which permits use, sharing, adaptation, distribution and reproduction in any medium or format, as long as you give appropriate credit to the original author(s) and the source, provide a link to the Creative Commons license, and indicate if changes were made. The images or other third party material in this article are included in the article's Creative Commons license, unless indicated otherwise in a credit line to the material. If material is not included in the article's Creative Commons license and your intended use is not permitted by statutory regulation or exceeds the permitted use, you will need to obtain permission directly from the copyright holder. To view a copy of this license, visit http://creativecommons. org/licenses/by/4.0/.
\end{abstract}

() The Author(s) 2018

\footnotetext{
'Department of Chemical Engineering, Tsinghua University, 100084 Beijing, China; ${ }^{2}$ Physical Sciences and Engineering Division, King Abdullah University of Science and Technology, Thuwal, Jeddah 23955-6900, Saudi Arabia and ${ }^{3}$ Shenyang National Laboratory for Materials Science, Institute of Metal Research (IMR), Chinese Academy of Sciences (CAS), Shenyang 110016, China
}

Correspondence: W-J. Hu (wjhu@imr.ac.cn) or L-J. Li (ljliv@tsmc.com)

These authors contributed equally: Chaojie Cui, Fei Xue.

Published online: 18 July 2018 